\title{
Oesophageal mucosal changes in patients with varices
}

\author{
R A J SPENCE, J M SLOAN, G W JOHNSTON, AND A GREENFIELD
}

From the Royal Victoria Hospital, Belfast

SUMmARY Histological examination of oesophageal rings removed at transection for varices reveals dilated intraepithelial blood filled channels. These are present in all oesophageal rings removed at transection for varices. A comparison has been made between rings removed from variceal patients with oesophageal rings removed during resections for oesophageal and gastric tumours. Although a small number of non-varices patients had intraepithelial channels they were significantly larger and more numerous in the varices patients $(p<0.01)$. Similarly, the area and number of dilated subepithelial channels (just beneath the epithelium) and the area of lamina propria channels were significantly greater in the varices patients $(p<0.05)$. Depth of papillae and thickness of the squamous epithelium were also significantly greater in the varices group $(\mathrm{p}<0.05$, $\mathrm{p}<0.01$ respectively). Under electron microscopy the channels were lined with flattened cells which were not typical of endothelial cells but stained positively for Factor VIII related antigen using indirect immunofluorescence. These channels may correspond to the cherry-red spots seen on endoscopy and may have a role in the pathogenesis of variceal haemorrhage.

Oesophageal transection in the management of varices is becoming increasingly popular with encouraging results. ${ }^{1}$ The procedure involves excision of a ring of oesophagus from the area of bleeding containing the full thickness of the wall followed by immediate anastomosis with a circular stapling gun. This provides the opportunity to examine tissue from the site of bleeding.

In a previous investigation to assess the incidence of oesophagitis in such tissue dilated blood-filled channels were consistently observed within the oesophageal epithelium in patients with varices. ${ }^{2}$ This study investigates the nature of these channels and assesses their significance.

\section{Methods}

\section{PATIENTS}

Oesophageal rings were obtained from 27 patients undergoing transection for varices. A control group of 17 rings was obtained, in similar fashion, from patients undergoing oesophageal anastomoses after resection of gastric or oesophageal tumours.

The varices group consisted of 17 men and 10 women with mean age of 53.9 years (SD 19.6 years).

\footnotetext{
Address for correspondence: Mr R A J Spence, FRCS. Department of Surgery. The Queen's University of Belfast. Institute of Clinical Science. Grosvenor Road. Belfast BT12 6BJ.

Received for publication 31 January 1983
}

The control group consisted of 10 men and seven women with mean age 60.7 years (SD 13.4 years). The aetiology of portal hypertension is shown in Table 1. In the control group four had squamous cell carcinoma of the oesophagus, 12 had adenocarcinoma of the stomach, and one patient had a carcinoid tumour of the stomach.

The rings, measuring $1-1.5 \mathrm{~cm}$ in length, were placed in mercuric formol, opened and the mucosal surface examined. Blocks of this tissue were taken in the longitudinal axis of the oesophagus and the entire circumference of the ring was blocked. Ten to 15 tissue blocks were obtained from each ring. The tissue was then routinely processed for histological examination. The sections were coded and four sections were selected randomly from each case for detailed histological examination.

The sections were projected on to 0.1 inch squared graph paper at a constant magnification $(\times 40)$. The outline of the various components of the section were traced on to the paper. By counting the squares, the following information was obtained on each section - the relative area of the squamous epithelium, relative area of lamina propria, relative area and number of dilated intraepithelial channels exceeding $0.05 \mathrm{~mm}$ in diameter (normal papillae were not counted). The relative area and number of subepithelial channels, defined as large blood filled channels lying immediately beneath the squamous epithelium, were also counted. Similarly the relative 
Table 1 Aetiology of portal hypertension

\begin{tabular}{lc}
\hline & Patients \\
\hline Micronodular cirrhosis & 16 \\
Macronodular cirrhosis & 6 \\
Portal vein thrombosis & 3 \\
Cystic fibrosis & 1 \\
Unknown* & 1 \\
\hline
\end{tabular}

* Normal liver biopsy.

area and number of dilated vessels within the lamina propria exceeding $0.05 \mathrm{~mm}$ diameter were counted.

In addition a microscopic eyepiece graticule was used to measure the thickness of the squamous epithelium in three randomly selected well orientated sections from each case. The thickness of the basal zone of the epithelium and the depth of penetration of papillae into the epithelium were also measured and expressed as percentages of the thickness of the squamous epithelium. The latter measurements were made on rings from four additional patients with varices in addition to the original 27. In two control patients the rings were unsuitable for assessment owing to poor orientation. Therefore, epithelial morphology was assessed in a total of 31 variceal rings and 15 control rings.

For examination by electron microscopy, tissue was fixed in Karnovsky's fixative, washed in phosphate and S-Collidine buffer, prestained with uranyl acetate, embedded in Epon and stained with uranyl acetate and lead nitrate. Sections were examined using an Hitachi H600 electron microscope.

In two specimens indirect immunofluorescence has been used to assess the presence of Factor VIII related antigen on cells lining the intraepithelial channels in frozen sections cut from unfixed material and post-fixed in acetone.

Factor VIII related antigen has been shown to be localised only on endothelial cells, platelets, and megakaryocytes. ${ }^{3}$ Indirect immunofluorescence has been shown to give reproducible results in determining the cellular origin of certain endothelial tumours ${ }^{4}$ and in investigating coagulation disorders. ${ }^{5}$

Oesophageal transection was carried out on four female normotensive greyhounds in order to see if the mucosal changes might be artefactual from the use of the gun. Mean weight was $23.4 \mathrm{~kg}$. In two dogs the procedures was carried out using the Russian gun and in two using the American gun. The oesophageal rings were processed in the standard fashion, stained with haematoxylin and eosin and examined with light microscopy.

The means of measured values within the two groups were compared using the Student's $t$ test.

\section{Results}

Dilated blood filled channels lying within (Fig. 1) and immediately beneath (Fig. 2) the squamous epithelium were found in all specimens from patients with portal hypertension. They were also found in $23 \%$ of specimens from non-varices patients although they were smaller and less numerous in this group. The channels were clearly visible on inspection of the mucosal surface of the oesophagus and were seen as haemorrhagic petechiae with occasional larger lesions resembling blood filled blisters.

These lesions were present in both deep and superficial parts of the squamous epithelium and

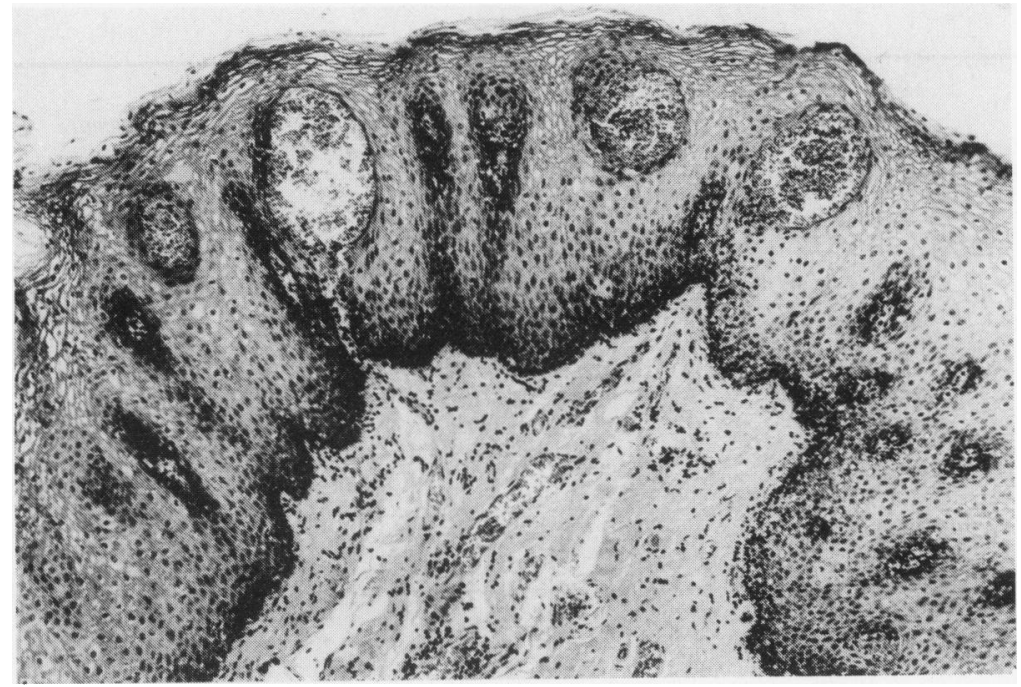

Fig. 1 Dilated blood-filled channels within squamous epithelium of oesophagus in patient with varices. Connection between one of channels and papillary capillary is seen. $H \& E \times 80$ (original magnification). 


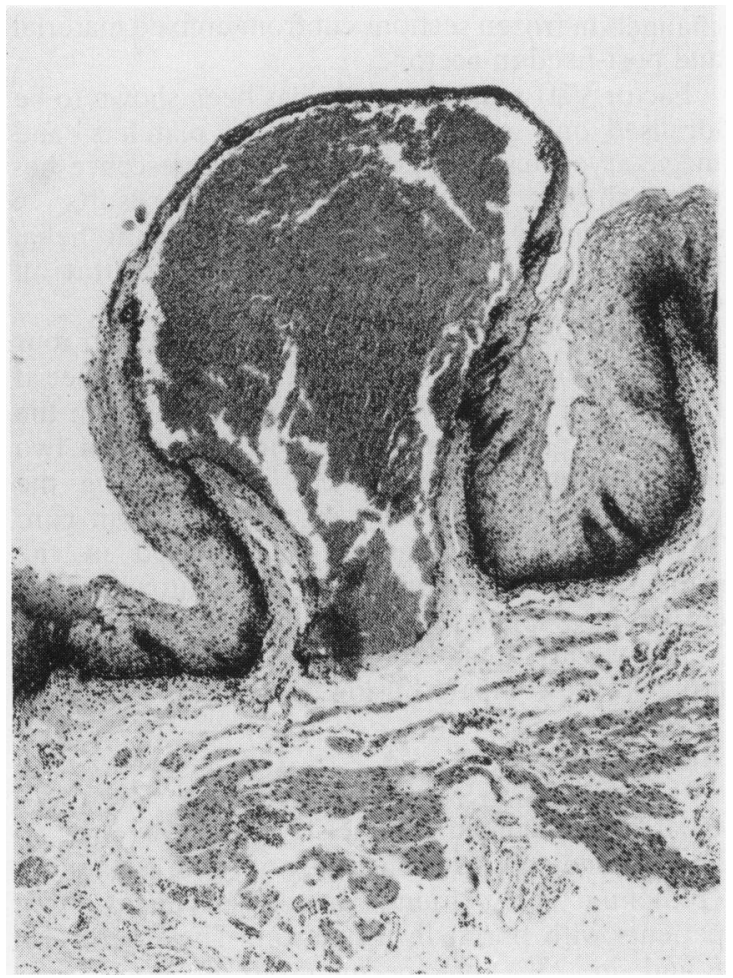

Fig. 2 Large subepithelial channel. Blood is separated from oesophageal lumen only by thin layer of squamous cells. $H \& E \times 40$ (original magnification).

occasionally were seen to have ruptured through the epithelial surface. The intraepithelial channels measured up to $0.3 \mathrm{~mm}$ in diameter. Subepithelial channels were larger and measured up to $2.5 \mathrm{~mm}$ in diameter. All channels were congested with red blood cells but no evidence of clotting of blood was seen within the lumen.

Intraepithelial channels were usually symmetrical. In some cases direct communication was seen between papillary capillaries and the dilated channels (Fig. 1). Serial sectioning was carried out on some blocks and confirmed that the dilated channels were derived from capillary vessels.

Channels within the squamous epithelium were lined by flattened cells. Methenamine silver staining showed they were not enclosed by basement membrane (Fig. 3) and were thus not conventional blood vessels. In some cases small fragments of basement membrane were present. Electron microscopy confirmed the absence of basement membrane and showed that the channels were not lined by endothelial cells but that the red blood cells were in direct communication with flattened squamous cells showing evidence of degeneration but identified by tonofilaments and desmosomes (Fig. 4).

Immunofluorescent staining for Factor VIII related antigen, however, showed the presence of the antigen lining the dilated intraepithelial channels despite the absence of endothelial cells (Fig. 5).

Table 2 shows the results of the comparison of single variables between the two groups. Highly significant differences were found in the number and size of epithelial channels, in the length of papillae within the squamous epithelium. These variables were all greater in the varices group $(p<0 \cdot 01)$. In addition, the ratio of epithelial channel area to squamous epithelium area was significantly higher in the varices group $(p<0 \cdot 01)$.

The thickness of the squamous epithelium, the

Table 2 Single variables test

\begin{tabular}{|c|c|c|c|c|}
\hline \multirow[b]{2}{*}{ Variable } & \multicolumn{2}{|l|}{ Mean $(S E)$} & \multirow[b]{2}{*}{ t value } & \multirow{2}{*}{$\begin{array}{l}\text { Significance } \\
\text { level }\end{array}$} \\
\hline & Control $(n=17)$ & Varices $(n=27)$ & & \\
\hline Area of squamous epithelium & $360 \cdot 00(38 \cdot 20)$ & $480 \cdot 00(40 \cdot 80)$ & $2 \cdot 13$ & \\
\hline Number of epithelial channels & $0 \cdot 28(0.085)$ & $2 \cdot 81(0 \cdot 41)$ & 5.96 & $\mathrm{p}<0.01$ \\
\hline Area of epithelial channels & $0 \cdot 37(0 \cdot 11)$ & $18 \cdot 43(4 \cdot 10)$ & $4 \cdot 40$ & $\mathrm{p}<0.01$ \\
\hline Area of lamina propria & $472 \cdot 00(175 \cdot 00)$ & $527 \cdot 00(77 \cdot 10)$ & $0 \cdot 29$ & \\
\hline Number of lamina propria channels & $4 \cdot 62(0 \cdot 65)$ & $5 \cdot 61(0 \cdot 57)$ & $1 \cdot 15$ & \\
\hline Area of lamina propria channels & $10 \cdot 85(2 \cdot 33)$ & $30 \cdot 25(4 \cdot 71)$ & $3 \cdot 70$ & $\mathrm{p}<0.05$ \\
\hline Number of subepithelial channels & $0 \cdot 08(0 \cdot 04)$ & $0.33(0.08)$ & $2 \cdot 81$ & $\mathrm{p}<0.05$ \\
\hline Area of subepithelial channels & $0.95(0.54)$ & $11.20(3.93)$ & $2 \cdot 58$ & $p<0.05$ \\
\hline Thickness of squamous epithelium* & $\begin{array}{l}0 \cdot 31(0 \cdot 038) \\
(\mathrm{n}=15)\end{array}$ & $\begin{array}{l}0.36(0.029) \\
(\mathrm{n}=31)\end{array}$ & $2 \cdot 86$ & $\mathrm{p}<0.05$ \\
\hline Basal zone thickness $\dagger$ & $\begin{array}{l}15 \cdot 40(3 \cdot 70) \\
(n=15)\end{array}$ & $\begin{array}{l}15.97(2.45) \\
(n=31)\end{array}$ & $0 \cdot 24$ & \\
\hline Depth of papillae $\dagger$ & $\begin{array}{l}48 \cdot 50(4 \cdot 20) \\
(n=15)\end{array}$ & $\begin{array}{l}60 \cdot 20(4 \cdot 10) \\
(n=31)\end{array}$ & $4 \cdot 81$ & $\mathrm{p}<0.01$ \\
\hline
\end{tabular}

${ }^{*} \mathrm{~mm} . \quad+$ Percentage of total thickness of squamous epithelium.

Except where stated the units refer to the number of graph paper squares. 


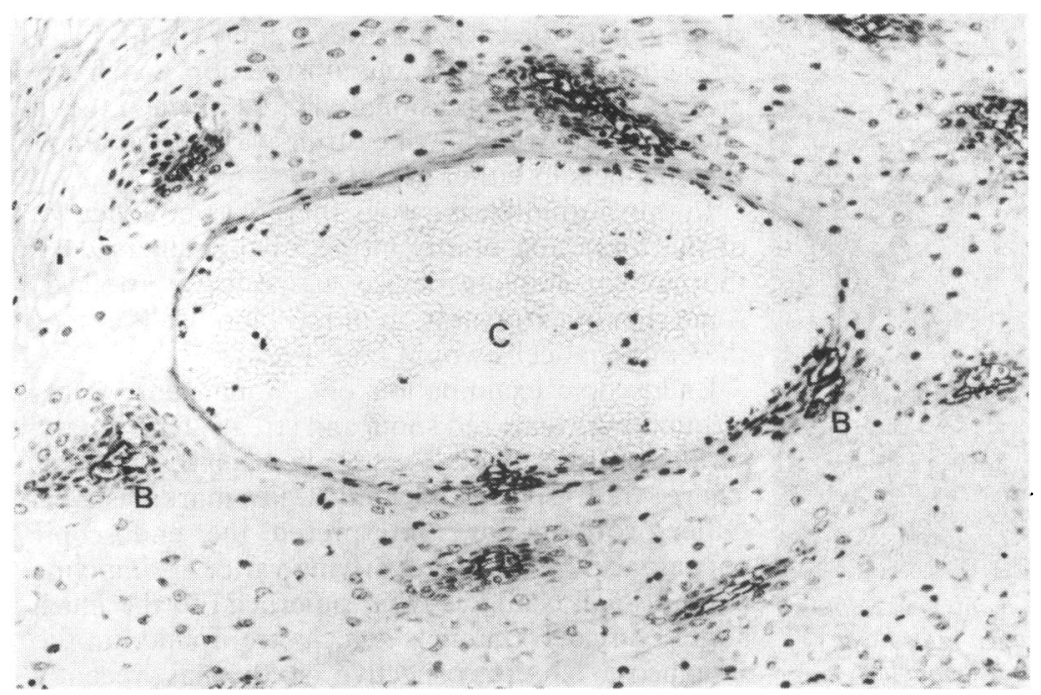

Fig. 3 Methenamine silver staining shows basement membrane $(B)$ lining intact intraepithelial capillaries. No basement membrane is seen lining intraepithelial channel (C). Methenamine silver $\times 150$ (original magnification).

number and area of the subepithelial channels and the area of dilated channels in the lamina propria were also significantly greater in the varices group $(p<0 \cdot 05)$. No significant difference was observed in the other variables assessed. The variables were also analysed with respect to age, the aetiology of portal hypertension and type of tumour, where applicable. No significant difference was found in any of the variables with respect to these parameters.

Numerous sections were obtained from the dog transected rings and none showed any formation of intraepithelial channels.

\section{Discussion}

We have observed intraepithelial channels in all oesophageal transection rings from patients with oesophageal varices. These channels have been described as vascular ducts by Cheli et al, ${ }^{6}$ as vascularised epithelium by others, ${ }^{7}$ and have been interpreted as evidence of oesophagitis.

Geboes and others ${ }^{8}$ have termed these channels congestive venules and have suggested that they represent the early changes in oesophagitis. They have described these intraepithelial 'venules' separated from the oesophageal lumen by only a few epithelial cells and they feel that this corresponds to the erythema seen on endoscopy in some patients with symptoms of reflux oesophagitis. ${ }^{9}$ Kobayashi and Kasugai have expressed similar views on their significance. ${ }^{10}$ Others have expressed doubt that the venular dilatation correlates with early oesophagitis. ${ }^{11}$ Evidence of oesophagitis as assessed

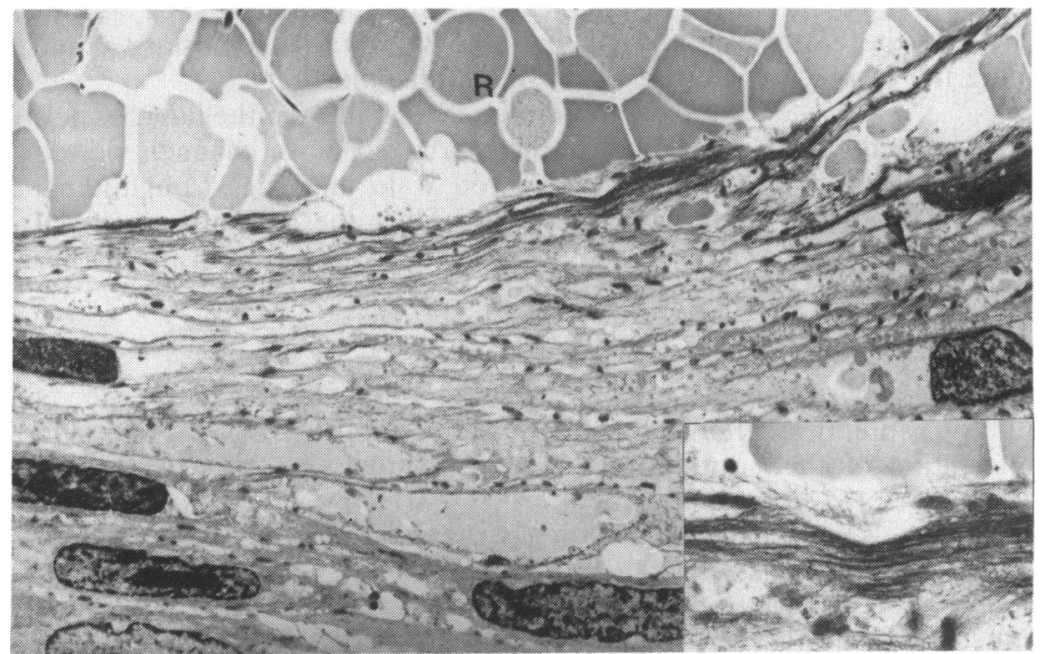

Fig. 4 Electron

photomicrograph of the edge of large intraepithelial channel. No basement membrane or endothelial cells are seen lining channel. Red blood cells $(R)$ appear to lie in contact with flattened squamous cells. Desmosomes joining the squamous cells and tonofilaments within cells are prominent. Original magnification $\times 1500$, inset $\times 8500$. 


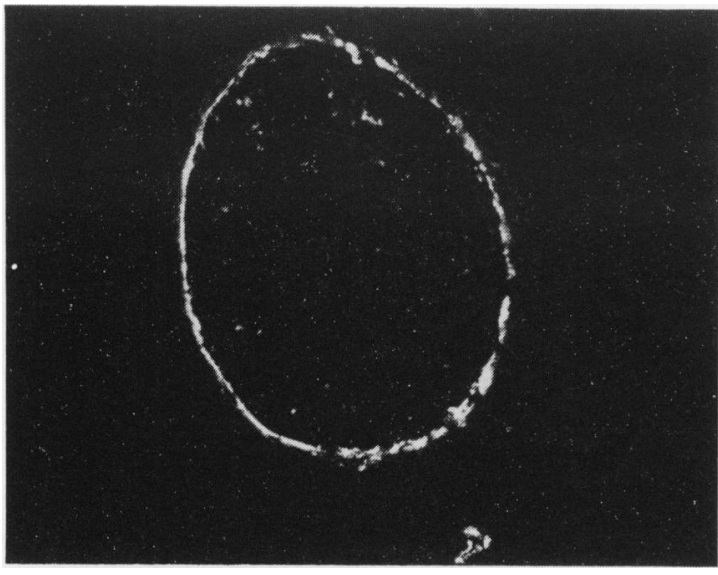

Fig. 5 Distribution of factor VIII related antigen around periphery of intraepithelial channel. Antigen is also seen within endothelial cells of nearby intact intraepithelial capillary. Indirect immunofluorescence $\times 100$ (original magnification).

using the criteria of Ismail-Beigi ${ }^{12}$ and Goldman and Antonioli, ${ }^{11}$ however, was seen in only $45 \%$ of our cases $^{2}$ despite the fact that the intraepithelial channels were present in all cases of oesophageal varices which were studied.

In the present study histological evidence suggests that the channels are not lined by endothelial cells and basement membrane and are thus not true blood vessels. These findings are similar to those of Geboes $e t$ al who found the channels were lined with flattened cells not resembling the basal epithelial cells. ${ }^{9}$ Indirect immunofluorescence for Factor VIII related antigen is a reliable technique for showing endothelial cells. ${ }^{13}$ Megakaryocytes and platelets also fluoresce positively with this technique but there was no evidence of platelets lining the channels under electron miscroscopy. It is therefore possible that the flattened cells lining the channels are functioning as endothelial cells.

Burnand et $\mathrm{l}^{14}$ have shown an increase in the size of the skin capillary bed in response to sustained local venous hypertension in the dog and similar findings have been reported in the human skin of the lower leg in the presence of venous hypertension. ${ }^{15}$ It is possible that prolonged portal venous hypertension may similarly induce an increase in the size of the capillary bed of the lower oesophagus and that the increased length of papillary capillaries, which we have shown, is a manifestation of this rather than of oesophagitis.

The possibility of these blood filled channels being artefact caused by the operative procedure must be considered as they have been found in a small proportion of the non-varices patients. A tumour in the region of the cardia, however, may readily cause an element of local venous obstruction and hence give rise to the occasional dilated intraepithelial channels. No evidence of clotting was seen in any of the channels in either group.

In our normotensive dogs there was no evidence of the formation of any intraepithelial channels. If the circular stapling device was causing artefacts, some sign of extravasation of red blood cells among the epithelial cells would be expected.

Endoscopic examination of oesophageal varices frequently reveals red spots and streaks lying on the surface of the varices. These have been described as 'cherry red' spots and 'red wale markings'. ${ }^{16} 17$ Other workers have interpreted the endoscopic appearances as 'varices overlying varices' ${ }^{18}$ implying dilated small channels lying superficial to the much larger variceal channels which are found in the submucosa. A retrospective study has recently suggested that the endoscopic findings accurately correlate with the risk of bleeding. ${ }^{19}$

This endoscopic interpretation corresponds to our histological findings. While we are unable to rule out that some of these channels may be artefact, nonetheless we have shown that they are larger and more numerous in transection specimens removed from patients with varices in comparison with non-variceal patients. This indicates that the small superficial mucosal vessels are more fragile as a consequence of long-standing hypertension and are thus more liable to rupture.

It is established that there is a sudden increase in pressure within oesophageal varices during coughing, sneezing, and yawning. ${ }^{20}$ It seems likely that fragile, poorly supported, congested channels extending close to the mucosal surface may rupture during such circumstances. Although such channels are of small calibre the rupture of such lesions especially in patients with poor haemostasis could give rise to substantial haemorrhage.

We propose that these intraepithelial channels may represent the cherry red spots (channels viewed end-on) and the red wale markings (longitudinal epithelial channels). Thus these small superficial channels may play an important role in the pathogenesis of bleeding oesophageal varices.

R A J Spence was in receipt of EHSSB Fellowship during the time of this study. Our thanks are due to Mr J C Sandford, Dr C H S Cameron, and Mr R Creighton for assistance with immunofluorescent studies, electron microscopy, and photomicrography respectively. We are also grateful to Miss S Campbell for typing the paper. 


\section{References}

1 Johnston GW. Six years experience of oesophageal transection for oesophageal varices, using a circular stapling gun. Gut 1982; 23: 770-3.

2 Spence RAJ, Sloan JM, Johnston GW. Oesophagitis in patients undergoing oesophageal transection for varices - a histological study. Br J Surg. 1983; 70: 332-4.

3 Jaffe EA. Synthesis of Factor VIII antigen by cultured human endothelial cells. Ann NY Acad Sci 1975; 240: 62-9.

4 Mukai K, Rosai J, Burgdorf WHC. Localisation of Factor VIII-related antigen in vascular endothelial cells using an immunoperoxidase method. Am J Surg Pathol 1980; 4: 273-6.

5 Holmberg L, Mannucci PM, Turesson I, Ruggeri ZM, Nilsson IM. Factor VIII antigen in the vessel walls in Von Willebrand's disease and haemophilia A. Scand J Haematol 1974; 13: 33-8.

6 Cheli R, Simon L, Elster K, Bocchini R. Oesophagitis in Italian and Hungarian asymptomatic subjects. Endoscopy 1982; 14: 1-3.

7 Skinner DB, Belsey RHR, Hendrix TR, Zuidema GD. Gastroesophageal reflux and hiatal hernia. Edinburgh: Churchill-Livingstone, 1972; 56-7.

8 Geboes K, Desmet V, Vantrappen G. Esophageal histology in the early stage of gastroesophageal reflux. Arch Pathol Lab Med 1979; 103: 205.

9 Geboes K, Desmet V, Vantrappen G, Mebis J, Vascular changes in the esophageal mucosa. Gastrointest Endosc 1980; 26: 29-32.

10 Kobayashi S, Kasugai T. Endoscopic and biopsy criteria for the diagnosis of esophagitis with a fiberoptic esophagoscope. Dig Dis 1974; 19: 345-52.

11 Goldman H, Antonioli DA. Mucosal biopsy of the oesophagus, stomach and proximal duodenum. Hum Pathol 1982; 13: 423-48.

12 Ismail-Beigi F, Horton PF, Pope CE. Histological consequences of gastrointestinal reflux in man. Gastroenterology 1970; 58: 163-74.

13 Hoyer LW, Santos de Los RP, Hoyer JR. Antihemophilic factor antigen. Localisation in endothelial cells by immunofluorescent microscopy. J Clin Invest 1973; 52: $2737-44$.

14 Burnaud KG, Clemenson G, Whimister I, Gaunt J, Browse NL. The effect of sustained venous hypertension on the skin capillaries of the canine hind limb. Br J Surg 1982; 69: 41-4.

15 Dodd H, Cockett FB. The pathology and surgery of the veins of the lower limb. Edinburgh: Livingstone, 1956: 362.

16 Dagradi AE, Stempien SJ, Owens LK. Bleeding esophageal varices. Arch Surg 1966; 92: 944-7.

17 Inokuchi $\mathrm{K}$. The general rules for recording endoscopic findings on esophageal varices. Jpn J Surg 1980; 10: 84-7.

18 Kumagaya Y, Makuuchi H, Tsuzuki T. Endoscopic classification of esophageal varices and its clinical significance. Stomach Intestine 1976; 11: 741-50.

19 Beppu K, Inokuchi K, Koyanagi N et al. Prediction of variceal haemorrhage by esophageal endoscopy. Gastrointest Endosc 1981; 27: 213-8.

20 Liebowitz HR. Pathogenesis of esophageal varix rupture. JAMA 1961; 175: 874-9. 